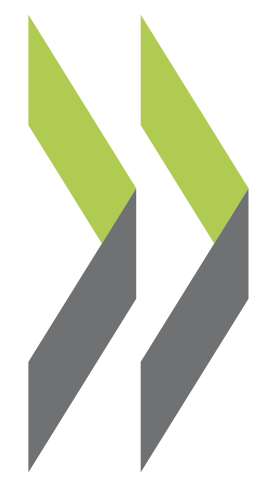

PEB Exchange, Programme on Educational Building 2003/05

\title{
Australia's Oak Valley \\ Aboriginal School
}

Graeme Allen,

Ingrid Kerkhoven,

Noelene Cox

https://dx.doi.org/10.1787/714337078782 


\section{AUSTRALIA'S OAK VALLEY ABORIGINAL SCHOOL}

In the Australian desert, a new school has been built for an Aboriginal community, replacing their previously transient school services. The design took into account the difficult site limitations and the community's needs and traditional values.

\section{Background}

The Oak Valley school is the second most remote in South Australia, and the community lacks basic services such as a sustainable supply of water and electricity. The settlement of Oak Valley was established in 1984 in an area of tribal significance to the Anangu people of the Greater Western Desert. Oak Valley is approximately $550 \mathrm{~km}$ northwest of Ceduna which is a small town $700 \mathrm{~km}$ west of Adelaide; the final $350 \mathrm{~km}$ is dirt road. The area has an extreme climatic range from in excess of $50^{\circ} \mathrm{C}$ to below freezing.

Initially community services were provided from mobile vans on a part-time basis, and, as the Oak Valley community would move about for cultural or family reasons, a "walk-about" school was taught three times a week on a tarpaulin until about 1990. Once the community became established in one area, schooling was provided under a shelter structure; furniture and resources were brought to Oak Valley by the teacher, who would come from over $300 \mathrm{~km}$ away. In the early 1990's the school moved into two caravans while waiting for a new school to be built.

The school's aim is to provide quality "ngapartji ngapartji" which is the Anangu concept of equal and reciprocal giving and sharing for everyone's benefit. The learning environment is one where two distinct cultures are given equal respect, and where a free flowing exchange of ideas, skills, knowledge and understandings flourish between Anangu and non-Anangu.

The school's concept statement underpins all the school's actions and decisions, and impacts on teaching methodologies and design. Methodologies based on Anangu students' preferred ways of learning rather than mainstream schooling translates, for example, into teaching spaces that allow room for working on the floor as well as at desks.

\section{Developing the brief}

The brief for the new school was developed over a substantial period of time, taking into account current directions in curriculum, small school facilities, community consultation, student surveys, Government Children's Services requirements and Aboriginal education expertise. Much consultation occurred between the school staff, community members, the Education Department and the Department for Administrative and Information Services on the proposed new facility. Students were asked for input and sketched and listed their preferences. A scale model of the school was constructed so that the community could more easily understand the proposal.

In addition to the formal briefing requirements, a number of site limitations had to be taken into account including:

- a pre-determined site location near the town generator and the subsequent noise problem;

- lack of water for building purposes and site amenities;

- the effects of prevailing winds and the prevalence of dust;

- the difficulty and high cost of transporting building materials and of on-site labour;

- the non-availability locally of spare parts and consumable items, such as non-standard wattage light bulbs, requiring careful consideration of the types of equipment used;

- the proliferation of temporary buildings on the site over the course of the project.

From the community's viewpoint it was crucial to develop and deliver "holistic" community-based care, health and welfare programmes. This meant providing appropriate kitchen, bathing and sleeping facilities.

\section{Resulting design}

The resulting design balances the brief and site limitations. The required layout and large windows precluded good orientation for part of the school, and prevented grouping buildings to create cooler, less dusty microclimatic conditions between them. This was discussed with the community during the design stage, who understood the concerns but felt that their priorities overrode these considerations. The design incorporated these factors and now provides an open, welcoming face to the community, whilst effectively turning its back on the prevailing winds and generator noise to the rear of the site, and achieving good orientation for all but one of the new buildings.

The enclosed outdoor areas, water tanks and remaining transportable buildings are grouped to help create microclimates and internal routes between the buildings. Outbuildings such as pit toilets were located some distance away for hygiene reasons. 


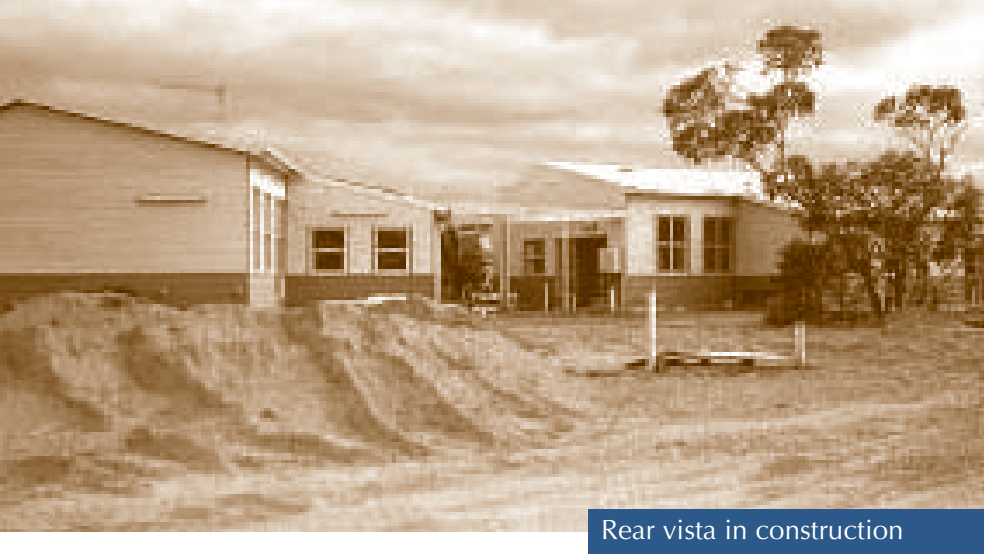

Due to the severe water, power and other limitations at Oak Valley, standard services responses such as evaporative air conditioning for arid and remote locations were not possible. All climate control operates on electricity with an interactive energy management system to minimise consumption and waste, and ceiling fans help reduce air conditioning use. The school has acknowledged that the performance of this air conditioning system may be less than optimum under extended severe conditions (such as $50^{\circ} \mathrm{C}$ days).

\section{Construction}

The successful tenderer proposed building the school as transportable buildings in Adelaide then pouring concrete in at ground level on the site, as this method would greatly reduce the need for on-site labour and shorten the construction period. Further community consultation was required to gain acceptance of this proposal, as transportable buildings were strongly rejected during initial community consultation. During the off-site construction period, the school and community were regularly kept appraised of progress. When advised that the buildings were on their way at last, the students and staff waited down the road for two hours to catch their first glimpse of the new school.

Verandahs, covered outdoor areas and site works were completed on site over a period of two months, and the school was finally occupied in early August 2002. Water had to be carted in from $350 \mathrm{~km}$ away for the concrete. Laying floor coverings was delayed to ensure the concrete that had to be poured inside the buildings had dried sufficiently. In the interim, loose carpet mats were used to enable occupation of the buildings as soon as possible. Ongoing landscaping by the school and community will continue to enhance its amenity.

\section{End result}

The end result is considered most successful by all involved and a great asset for the school children of Oak Valley. The community is proud of its uniquely designed school that fits in with their needs. The new school delivers many of the benefits visualised over its long conception, including:

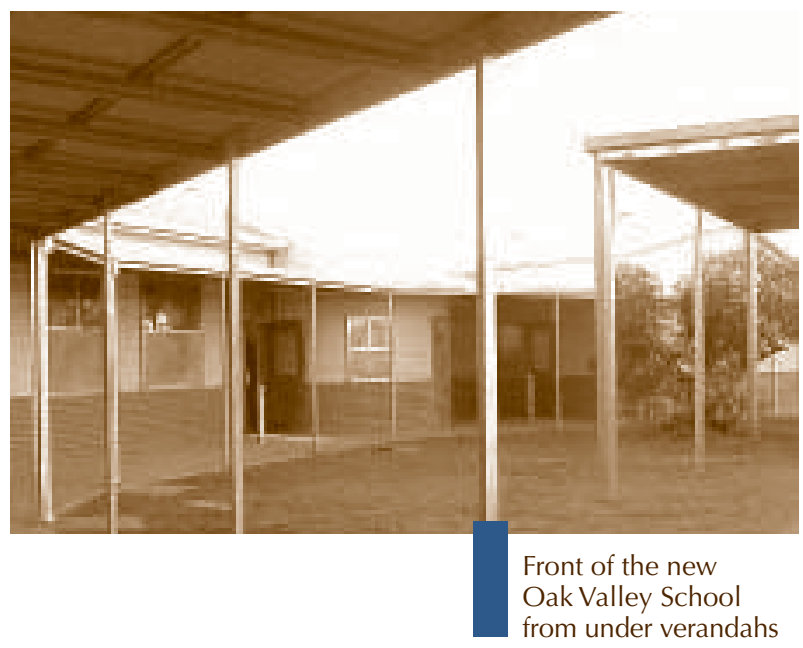

- vibrant new facilities that blend in well with community buildings; the finishes are similar to those of the community housing which make students and the community feel more at home at the school;

- attractive interiors with hard wearing finishes, including plywood walls and ceilings that require little maintenance and provide acoustic attenuation;

- a design which is compact yet provides appropriate spaces for staff and students;

- bulk rainwater storage tanks (sevens tanks providing storage of nearly 100000 liters);

- maximum flexibility in all areas; already Oak Valley has been able to accommodate additional administrative staff, building change of use and a proposed change of emphasis in its outdoor recreation areas;

- multi-purpose covered outdoor learning areas, which can also be accessed by the community for after-hours classes;

- good day-lighting (important as the power frequently fails).

A number of these features will be useful in the design of other Aboriginal schools in the ongoing programme of Aboriginal school redevelopments in South Australia.

The new school buildings at Oak Valley cost AUD 1.5 million, approximately AUD 2300 per square metre.

\section{Authors}

Graeme Allen, Major Projects Coordinator for the Department of Education and Children's Services (DECS), has worked extensively in the Aboriginal Lands and has developed a strong rapport with local communities.

Ingrid Kerkhoven, architect and interior designer for the Department for Administrative and Information Services 
(DAIS) and responsible for the building design of the project, has longstanding experience in the Aboriginal Lands.

Noelene Cox, a dedicated teacher with 11 years' teaching experience and currently Acting Principal of Oak Valley Aboriginal School, has a strong interest in Aboriginal Education and places importance on forming partnerships with the community to achieve educational outcomes for their students.

For further information, contact:

Graeme Allen, DECS, e-mail: allen.graeme@saugov.sa.gov.au Ingrid Kerkhoven, DAIS, e-mail: kerkhoven.ingrid@saugov.sa.gov.au PEB is keen to hear of other facilities designed to meet the educational needs of cultural and ethnic minority communities. If there is sufficient interest it is hoped to organise an international experts' meeting on this topic in 2004 or 2005.

\section{PUBLIC/PRIVATE PARTNERSHIPS IN QUEBEC}

For some time now in Quebec (Canada), the Treasury Board Secretariat (TBS) has been promoting public/ private partnerships (PPP) as a solution to the need to rehabilitate the public building stock. The TBS describes this as the best value-for-money solution for liquidating the maintenance and operating deficits of public buildings such as schools. It also elaborates on the main benefits of this solution:

- savings across the board;

- a reduction in costs over the duration of the project/ service;

- financial participation by the private sector;

- better risk spreading;

- faster project delivery;

- more creative or innovative solutions;

- long-term contracts;

- performance measurement and performance incentives;

- enhanced public management.

The distinctive feature of the Treasury Board Secretariat's solution is the scale of the proposed partnerships. Rather than setting up PPPs for more classic types of subcontracting, the idea is to extend the principle to every aspect of public building management. The correct term is therefore outsourcing. The idea is to manage one contract rather than several. Are our organisations ready to meet the challenge? What will the impact of PPPs be on existing collective agreements reached by regular employers, or on current laws and ministerial directives? Is the solution cost-effective? How can management performance be assessed before and after a PPP?

\section{Contracts between public organisations and private firms}

The first step in answering these questions is to look at types of service delivery other than in-house provision. They fall into three main categories:

- Contract of supply: the client merely specifies the kind of service required and agrees on a price with the supplier.

- Subcontracting: the client requires work that is more complicated or not entirely standard. Subcontractors are left relatively free to decide how the work will be carried out.

- Outsourcing: this implies a close link between the client and the outsourcing company, two important factors being networks and the duration of the contract (clan-type link between strategic allies).

Public building managers should study the situation closely before choosing the best type of public/private partnership for their organisation. Their choice must be based on an analysis of the situation as it stands compared with the situation they would like to see. How do they proceed? By looking at the production costs and information costs of the service that might be outsourced.

When it comes to production costs, there are two basic questions:

- Does the public organisation have the right technology? Specialisation by private firms usually means cost savings through learning, innovation and economies of scale.

- Can the public organisation deliver more economically? Vertical integration or in-house delivery may ensure that subcontractors do not "cream off" profits. A degree of organisational inefficiency may even be tolerated to ensure that the organisation is not exploited.

As for information costs, it is important to take an holistic view. What are the transaction costs for the resources used or foregone by managing the work involved in the services to be outsourced?

- Upstream costs of service provision: research and information costs, cost of negotiating, making decisions and drawing up contracts.

- Downstream costs of service provision: inspection and monitoring costs (performance indicators), cost of adjusting to unforeseen events, cost of disputes and litigation, liability costs and residual losses owing to insufficiently or inappropriately co-ordinated performance. 